\title{
O NÍVEL DE TRANSPARÊNCIA DOS PORTAIS ELETRÔNICOS: CASO DAS CAPITAIS BRASILEIRAS
}

\section{Electronic Portal transparency level: the CASE OF BRAZILIAN CAPITALS}

\author{
Kliver Lamarthine Alves Confessor ${ }^{1}$, Jailza Mendes da Costa ${ }^{2}$, \\ Fernando José Vieira Torres ${ }^{3}$, Joséte Florencio dos Santos ${ }^{4}$
}

${ }^{1}$ Universidade Federal do Vale do São Francisco - adm.kliver@gmail.com

${ }^{2}$ Universidade Federal da Paraíba - jailzamendes@live.com

33niversidade Federal da Paraíba - fjttorres@hotmail.com

${ }^{4}$ Universidade Federal de Pernambuco - jfs@ufpe.br

\begin{tabular}{|c|c|}
\hline INFORMAÇÕES & RESUMO \\
\hline $\begin{array}{l}\text { Palavras-chave: } \\
\text { Controle Social; } \\
\text { Portais Eletrônicos } \\
\text { Oficiais; } \\
\text { ITGP-M. }\end{array}$ & $\begin{array}{l}\text { Esta pesquisa verificou o nível de transparência nos portais das prefeituras } \\
\text { das capitais brasileiras, tendo como balizador o Índice de Transparência da } \\
\text { Gestão Pública Municipal (ITGP-M) de CRUZ et. al. (2012) e identificou } \\
\text { a relação do nível de transparência desses municípios com a população e o } \\
\text { Índice de Desenvolvimento Humano (IDH), para este fim, utilizou a estatística } \\
\text { descritiva. Ao analisar o portal eletrônico oficial das capitais brasileiras os } \\
\text { resultados obtidos permitem dizer os níveis de transparência das capitais estão } \\
\text { distantes do esperado pela legislação e literatura específica, portanto, chama a } \\
\text { atenção para a necessidade de medidas fiscalizadoras e reguladoras para que } \\
\text { a legislação seja aplicada. São Luiz - MA destacou-se como a capital menos } \\
\text { transparente enquanto João Pessoa - PB como aquela mais transparente. Ao } \\
\text { relacionar os resultados do ITGP-M, com a quantidade de habitantes e o nível } \\
\text { de IDH, verificou-se que estes fatores não exercem influência sobre o IGP-M } \\
\text { confrontando o que dizem a teoria de controle social e accountability. }\end{array}$ \\
\hline INFORMATION & ABSTRACT \\
\hline $\begin{array}{l}\text { Keywords: } \\
\text { Social Control; } \\
\text { Official Electronic Por- } \\
\text { tals; } \\
\text { ITGP-M. }\end{array}$ & $\begin{array}{l}\text { This research verified the level of transparency in the portals of the prefectures } \\
\text { of the Brazilian capitals, having as reference the Transparency Index of } \\
\text { Municipal Public Management (ITGP-M) of CRUZ et. al. (2012) and identified } \\
\text { the relationship between the level of transparency of these municipalities with } \\
\text { the population and the Human Development Index (HDI), for this purpose, } \\
\text { used descriptive statistics. When analyzing the official electronic portal of the } \\
\text { Brazilian capitals, the results obtained allow to say the levels of transparency } \\
\text { of the capitals are far from what is expected by the legislation and specific } \\
\text { literature, therefore, draws attention to the need for inspection and regulatory } \\
\text { measures for the legislation to be applied. São Luiz - MA stood out as the } \\
\text { least transparent capital while João Pessoa - PB as the most transparent. When } \\
\text { relating the results of the ITGP-M, with the number of inhabitants and the level } \\
\text { of HDI, it was found that these factors do not influence the IGP-M, confronting } \\
\text { what the theory of social control and accountability say. }\end{array}$ \\
\hline
\end{tabular}




\section{INTRODUÇÃO}

O diálogo entre a administração pública e a sociedade passa pelo viés de alguns conceitos que vem sendo discutidos na perspectiva de pressionar o Estado. Entre estes conceitos, temos a Governança Corporativa (GC), que vem sendo adaptada ao setor público, trazendo os princípios de transparência, equidade, accountability e a responsabilidade corporativa. Ao se utilizar da Governança para gerir o setor público de maneira eficiente e eficaz, o princípio da transparência é essencial diante as ações de cada gestor público, que devem ser expostas de maneira clara e objetiva, para que assim as sociedades reivindiquem atos condizentes com os interesses da coletividade.

Conforme o TCU (2002) a construção de capacidades estatais não pode prescindir do princípio da transparência uma vez que a maior abertura e compartilhamento de informações torna o público capaz de decidir e fazer escolhas políticas, e, portanto, aumenta a accountability e contribui para a redução da corrupção.

Interesses da coletividade, que vem respaldado pelo Estado Democrático de Direito, que na Constituição de 1988, deixa bem claro que o poder emana do povo, povo este, que não se trata apenas de um número, mas aquele que unidos podem exercer a soberania popular, e devem ser tratados iguais perante a lei. Assim sendo, Correa (2003) destaca que na década de 1980 houve uma maior mobilização política no que concerne ao debate sobre a participação da sociedade civil quanto ao controle sobre o Estado.

Controle este que vem a ser denominado de Controle Social, e vem ganhando notoriedade, de modo que o papel do cidadão não é realizado apenas no momento eletivo, mas passa a ser exercido de maneira incisiva, quando a gestão localiza-se nas mãos dos representantes, de modo que todas as ações sejam publicizadas, passando a ser transparente para com a sociedade. Nesse sentido, o Controle Social possui como perspectiva a participação da sociedade nos planos, programas, projetos, acompanhamento de suas execuções e definição da alocação de recursos junto aos órgãos públicos (COOREA, 2003).

Desta forma, na busca pela gestão dos recursos públicos de forma eficiente, faz-se necessário a participação da sociedade, que para isso precisa estar bem informada quanto a destinação dos recursos públicos se estão sendo alocados em prol da coletividade. Para isso as informações devem chegar ao cidadão de maneira tempestiva e clara, para que assim possam exercer o controle social, e uma das formas de expor estes dados é por meio de portais eletrônicos oficiais, que de acordo com a legislação devem dispor de informações da gestão, em tempo real.

Assim, diversas pesquisas vêm analisando se estes portais estão de fato contribuindo na prestação de contas para o cidadão, por exemplo, Cruz et al. (2012) em estudo realizado nos maiores municípios brasileiros constatou que existem baixos níveis de transparência e que os resultados não condizem com o nível de desenvolvimento socioeconômico alcançado pelos municípios. Raupp e Pinho (2010) em análise nos portais eletrônicos das câmaras de vereadores de municípios com mais de 50.000 habitantes, no estado de Santa Catarina, verificou que havia baixa capacidade destes, viabilizar a construção da accountability.

Verificando-se que a ideia de disponibilizar informações claras, que possam direcionar o cidadão quanto a alocação dos recursos de seu município, ainda esteja em fase bem inicial, a presente pesquisa teve como objetivo geral a verificação do nível de transparência nos portais das prefeituras municipais das capitais brasileiras. E para sua execução foram definidos os seguintes objetivos específicos: analisar se todas as capitais continham portais eletrônicos ofi- 
ciais; Análise dos portais das prefeituras das capitais brasileiras, tendo como base o ITGP-M, verificando se os portais continham ou não as informações que compõem o índice, criando assim um ranking da porcentagem alcançada por cada capital brasileira; E esboçar um perfil por região, levando em consideração, variáveis como a população e o IDH.

\section{FUNDAMENTAÇÃO TEÓRICA}

\subsection{Governança no setor público}

Governança no setor público pode ser definida como a capacidade que uma determinada instituição tem para formular e implementar suas políticas proporcionando o bem-estar da sociedade e atendendo aos preceitos éticos e legais. Segundo o Instituto Brasileiro de Governança Corporativa (IBGC), a Governança é totalmente conectada a necessidade de prestar contas.

O relatório publicado em 1992, pelo Comitê formal de aspectos financeiros da Governança Corporativa (Cadbury Report, 1992) a definiu como um sistema pelo qual as organizações são dirigidas e controladas, em que lista três dos seus princípios: transparência, Integridade e Responsabilidade em Prestar Contas, descritos no Quadro 1 com enfoque para o setor público.

Quadro 1. Princípios da Governança Pública

\begin{tabular}{|c|l|}
\hline Princípio & \multicolumn{1}{c|}{ Conceito } \\
\hline \multirow{2}{*}{ Transparência } & $\begin{array}{l}\text { "O governo deve ir ao cidadão para se justificar; deve procurá-lo, por meio de } \\
\text { cartilhas, informativos dirigidos e instrumentos similares que, de fato, "digam } \\
\text { algo" àquele cidadão sobre como os recursos públicos estão sendo empregados } \\
\text { em prol do bem comum (pois este deve ser o fim precípuo de qualquer gestor } \\
\text { público)". (ALVES, 2011, p. 271); } \\
\text { “É a parte central para a boa governança”. (BATTETT, 2011, p. 5). }\end{array}$ \\
\hline Integridade & $\begin{array}{l}\text { Refere-se ao compromisso de que o governo aja de modo coerente e fundamen- } \\
\text { tado em princípios com todos os seus cidadãos, a fim de estender a um padrão de } \\
\text { justiça e equidade (DWORRKIN, 2003). } \\
\text { Compreende os procedimentos honestos e perfeitos. É baseada na honestidade, } \\
\text { objetividade, normas de propriedade, probidade na administração dos fundos e } \\
\text { recursos públicos e na gestão dos negócios da entidade. (PSC/IFAC, 2001) }\end{array}$ \\
\hline Responsabilidade em pres- \\
tar contas
\end{tabular}
Fonte: Elaborado pelos Autores (2016).

Assim, observa-se a Governança Pública como uma ligação de mão dupla entre quatro elementos: a Administração, a Supervisão, o Controle e a accountability, que significa responsabilidade em prestar contas. (TIMMERS, 2000). O inter-relacionamento entre a administração, a supervisão, e a responsabilidade em prestar contas, corrobora para uma visão administrativa em termos de eficácia, eficiência e efetividade, agindo em conformidade com regulamentos e corroborando para o controle financeiro (TIMMERS, 2000).

A Governança Pública está atrelada ao uso eficiente, eficaz e efetivo dos recursos públicos. A Administração Pública passa a ser visualizada pelos resultados apresentados, sendo o sucesso do governo avaliado pelo cidadão. Assim, a Governança do setor público é medida por meio das melhores práticas que envolvem a transparência e a prestação de contas de suas atividades para a sociedade, tendo em vista que o cidadão é o principal interessado em saber como está a propagação de suas ações e se estão alcançando bons resultados. 
A nova gestão pública está voltada para a prestação de contas, que por sua vez está associada ao fato de que população estaria mais próxima do governo e cobrando ações e demonstrativos dos projetos que realmente devem ser feitos na administração pública. Além disso, é importante observar que existe uma diferença entre transparência fiscal e publicidade fiscal, uma vez que a publicidade consiste em tornar a informação disponível publicamente, sem observar plenamente a clareza, confiabilidade, objetividade e voluntariedade que configuram a transparência. Nesse sentido, Alves (2011) relata que não é suficiente que a informação esteja disponível, e sim, imprescindível que esteja pública, detalhada, precisa e clara, posto que do contrário, não atende ao princípio da transparência.

\subsection{Controle Social}

A concepção de Controle Social é cunhada a partir da década de 70 quando cresceram os movimentos sociais pela democracia. No final dos anos 80, segundo Correia (2003) a sociedade passou a exercer o controle por meio da fiscalização dos papeis do Estado e, consequentemente, sobre os recursos públicos direcionando-os na direção dos interesses da coletividade.

Tal controle pode ser realizado em dois momentos: Quando são definidas as políticas a serem implementadas e no momento da fiscalização, no qual são acompanhadas e fiscalizadas a implementação da política pública e aplicação dos recursos financeiros. Ou seja, o Controle Social é uma forma de compartilhar o poder de decisão entre sociedade e Estado no que concerne as políticas públicas, configurando-se como uma expressão da democracia e da cidadania.

Assim, entende-se como sendo a capacidade que a sociedade tem de intervir nas políticas-públicas uma vez que esta contribui com o Estado na definição de prioridades e na elaboração dos planos de ação nas esferas municipais, estaduais e federais. Nesse sentido, o Controle Administrativo pode ser expresso sob três perspectivas: controle interno, externo e controle social, conforme Pestana (2012), apresentados no Quadro 2.

Quadro 2. Perspectivas do Controle Administrativo

\begin{tabular}{|c|l|}
\hline \multicolumn{1}{|c|}{ Autor } & \multicolumn{1}{c|}{ Conceito } \\
\hline Controle Interno & $\begin{array}{l}\text { Tem como finalidade avaliar o cumprimento das metas e destinação dos recursos esta- } \\
\text { belecidos bem como assegurar a eficácia e eficiência da gestão pública. }\end{array}$ \\
\hline Controle Externo & $\begin{array}{l}\text { É realizado pelo órgão alheio ao que se realizou o ato, e consiste na verificação do } \\
\text { exercício regular da competência atribuída pela lei, ou seja, são órgãos externos no qual } \\
\text { fiscalizam as ações da administração pública e o seu funcionamento. }\end{array}$ \\
\hline Controle Social & $\begin{array}{l}\text { É a integração da sociedade com a administração pública, sob a finalidade de solucionar } \\
\text { problemas. É a descentralização do Estado motivando grupos de pessoas a solucionar } \\
\text { problemas sociais, sendo aparado constitucional e legalmente. Ou seja, é a participação } \\
\text { social na gestão pública. }\end{array}$ \\
\hline
\end{tabular}

Fonte: Elaborado pelos Autores (2016)

Diante do exposto, percebe-se que o Controle Social configura-se como um instrumento democrático no qual há a participação dos cidadãos no exercício do poder e que a vontade social se sobrepõe como fator de avaliação para a criação de metas a serem alcançadas por meio das políticas públicas. Portanto, é uma maneira de estabelecer um compromisso entre o poder público e a sociedade com a finalidade de propor alternativas para os problemas econômicos e sociais e que ao ser entendido como uma forma de fiscalização e controle, a própria sociedade pode contribuir no planejamento, na realização e na avaliação das atividades do governo. 
O Controle Social deve ser entendido como o controle da sociedade sobre o destino das políticas sociais para que atendam aos reais interesses da maioria da população. Isto posto, o controle social possui o importante papel de garantir o atendimento das necessidades prioritárias da população, melhorando os níveis de qualidade dos serviços oferecidos e também fiscalizar a aplicação dos recursos públicos.

Destarte, a participação da sociedade no Controle Social fortalece as políticas públicas e as tornam adequadas às necessidades da coletividade, portanto, mais eficientes. Nesse sentido, verifica-se que este tipo de controle contribui para a democratização da gestão pública uma vez que envolve diversos atores da sociedade, cada qual com suas necessidades e interesses específicos. No entanto, Tavares, Martins e Figueiredo (2013) lembram que a efetividade do Controle Social pressupõe a transparência nas ações de governo e a devida competência de qualquer cidadão em conhecer e interpretar as informações disponibilizadas pelos órgãos públicos.

Sacramento e Pinho (2007) e Figueiredo e Santos (2014) declaram a transparência como um instrumento capaz de contribuir para redução da corrupção no espaço público e de aumentar a democracia entre o Estado e a sociedade, posto que a transparência permite ao cidadão acompanhar a gestão pública e favorece o crescimento da cidadania. A transparência da gestão fiscal relaciona-se à disponibilidade crescente e tempestiva de informação econômica, social e política sobre a administração em meios eletrônicos de acesso público (PAIVA; ZUCCOLOTTO, 2009; SUZART, 2012).

São três as dimensões da transparência das contas públicas: a publicidade, a compreensibilidade e a utilidade para decisões. A primeira entende pela ampla e tempestiva divulgação por diversos meios, enquanto a segunda refere-se à acessibilidade da linguagem - que esteja orientada ao perfil dos usuários e em boa formatação. A última dimensão fundamenta a relevância das informações e a sua confiabilidade (PLATT NETO; CRUZ; VIEIRA, 2006). Com base nessas dimensões, verifica-se que a transparência vai além de apenas permitir acesso aos dados, ela proporciona que o cidadão obtenha e possa interpretar a informação completa, relevante, oportuna, pertinente e confiável a respeito da administração pública (GRAU, 2005).

Para Cavalcante (2008), publicidade, clareza, relevância, confiabilidade e a oportunidade são elementos básicos da transparência, assim, para classificar a administração pública como transparente não basta que a informação esteja acessível à população, é necessário que a informação atenda esses requisitos. O princípio da transparência está associado à divulgação de informações que permitam a averiguação das ações dos gestores e a consequente responsabilização por seus atos. Na definição de transparência são identificadas características em relação à informação completa, objetiva, confiável e de qualidade, ao acesso, à compreensão e aos canais totalmente abertos de comunicação (ALÓ, 2009).

Conforme a Lei de Responsabilidade Fiscal em seu artigo 48, a transparência da gestão fiscal é assegurada pela divulgação dos planos dos orçamentos e das prestações de contas, bem como o relatório resumido da execução orçamentária e do relatório de gestão fiscal. Ademais, LRF estabelece regras em prol de uma maior transparência das contas públicas dos entes federativos, determinando a divulgação em tempo real de informações pormenorizadas sobre sua execução orçamentária e financeira, além de divulgação periódica de relatórios, realização de audiências públicas regulares e na prestação de contas dos chefes dos poderes (CRUZ et al., 2012). 


\section{3 Índice de Transparência da Gestão Pública Municipal (ITGP-M)}

O Índice de Transparência da Gestão Pública Municipal (ITGP-M) de CRUZ et al. (2012) tem como parâmetro o Índice de transparência de los ayuntamientos (ITA), que foi criado pelo Comitê espanhol de Transparência Internacional, que teria pontos referentes aos códigos internacionais de transparência e governança e cujas categorias de analise estão dispostas no Quadro 3.

Quadro 3. Categorias de informações constantes do ITGP-M

\begin{tabular}{|c|c|c|c|}
\hline Código & Categorias de Informações & $\begin{array}{l}\text { Pontuação } \\
\text { Máxima }\end{array}$ & Objetivos de divulgação \\
\hline $\mathrm{C} 1$ & $\begin{array}{l}\text { Informações gerais sobre o municí- } \\
\text { pio, gestor municipal e vereadores }\end{array}$ & 10 & $\begin{array}{l}\text { Informar sobre os ocupantes de cargos eleitos } \\
\text { e a estrutura administrativa municipal. }\end{array}$ \\
\hline $\mathrm{C} 2$ & $\begin{array}{l}\text { Legislação municipal e instrumen- } \\
\text { tos de planejamento municipal }\end{array}$ & 11 & $\begin{array}{l}\text { Permitir acesso à legislação municipal ordi- } \\
\text { nária e também aos instrumentos de plane- } \\
\text { jamento que orientam a gestão orçamentária } \\
\text { (receitas e despesas). }\end{array}$ \\
\hline $\mathrm{C} 3$ & $\begin{array}{l}\text { Informações financeiras, relatórios } \\
\text { contábeis e fiscais }\end{array}$ & 36 & $\begin{array}{l}\text { Disponibilizar relatórios sobre a situação } \\
\text { econômico-financeira municipal, no tocante } \\
\text { à execução do orçamento, gestão dos ativos e } \\
\text { das dívidas do município. }\end{array}$ \\
\hline $\mathrm{C} 4$ & $\begin{array}{c}\text { Interação com os cidadãos e com a } \\
\text { sociedade }\end{array}$ & 19 & $\begin{array}{l}\text { Informar sobre os serviços prestados on-line } \\
\text { no portal do município e possibilidades de } \\
\text { interação e participação sobre as preferências } \\
\text { governamentais. }\end{array}$ \\
\hline C5 & Análise do portal do município & 7 & $\begin{array}{l}\text { Possibilitar a análise das condições de } \\
\text { acessibilidade e navegabilidade do portal do } \\
\text { município. }\end{array}$ \\
\hline C6 & $\begin{array}{l}\text { Informações quantitativas e quali- } \\
\text { tativas sobre a gestão }\end{array}$ & 60 & $\begin{array}{l}\text { Disponibiliza informações de áreas cujas } \\
\text { condições têm impacto direto na vida dos } \\
\text { cidadãos: política tributária, administração, } \\
\text { licitações e compras, segurança pública, } \\
\text { educação, cultura, esporte e lazer, habitação e } \\
\text { urbanismo, saúde, saneamento básico, gestão } \\
\text { ambiental, atividades econômicas, trabalho e } \\
\text { transportes. }\end{array}$ \\
\hline
\end{tabular}

Fonte: CRUZ et al. (2012)

O ITGP-M constitui-se de 119 itens que totaliza 143 pontos, que de acordo com a existência ou não dos dados explicitados, em sua maioria é contabilizado seguindo uma lógica binária, "1" para a existência e "0" para não existência. Contudo no que diz respeito a algumas informações contidas na categoria 3, que envolve informações financeiras, relatórios contábeis e fiscais, a pontuação é referendada por uma escala proporcional de sua periodicidade, como está previsto na Lei de Responsabilidade Fiscal - LRF.

Ao ser aplicado por Cruz et al. (2012) nos maiores municípios brasileiros, os resultados apresentaram a menor pontuação de 15 pontos (10,5\%) e a maior pontuação de 122 pontos (85\%), e como se tratava de municípios brasileiros que correspondiam a $60 \%$ do PIB brasileiro, tendo em vista a quantidade da população, este resultado em relação ao nível de transparência se tornou incompatível com seu desenvolvimento socioeconômico. Mas, apresentou direção positiva, no sentido que melhores condições socioeconômicas tendem a implicar maior nível de transparência por parte dos municípios. 


\section{METODOLOGIA}

Segundo Marconi e Lakatos (2007) método é o conjunto de atividades sistemáticas e racionais utilizadas pelos cientistas para obter dados válidos e verdadeiros, definindo os caminhos a serem percorridos. Convém destacar que a presente pesquisa segue a metodologia de Raupp e Pinho (2010) para avaliação da transparência da gestão pública. Estes autores construíram o modelo de análise a partir de experiências anteriores de diversos autores e instituições (AKUTSU, 2002; PINHO, 2002; DINIZ, 2000; MORAES, 2004; PRADO, 2004).

Para o desenvolvimento desse trabalho, fez-se necessário pesquisar se todas as capitais continham portais eletrônicos oficiais; analisar os portais das prefeituras das capitais brasileiras, tendo como base o ITGP-M, verificando se os portais continham ou não as informações que compõem este índice, criando assim um ranking da porcentagem alcançada por cada capital brasileira e por fim, traçar um perfil por região, levando em consideração, variáveis como a população e o IDH, como sugeriu Cruz et al (2012).

Quanto aos objetivos, a pesquisa é de cunho exploratório, descritivo e longitudinal. A pesquisa exploratória, conforme Gil (2008), propõe a discussão de um tema até então pouco abordado. E descritivo porque possui como objetivo verificar o nível de transparência nos portais das prefeituras municipais das capitais brasileiras. De acordo com Vergara (2010), pode-se classificar a pesquisa quanto aos meios, como pesquisa documental, que é a investigação realizada em documentos conservados no interior de órgãos públicos ou privados de qualquer natureza, no caso da presente pesquisa a principal fonte de consulta de informações são os portais das prefeituras municipais das capitais brasileiras.

As informações foram coletadas por meio de um protocolo de observação, que para Creswell (2007), é utilizado para registrar dados de observações múltiplas durante a realização de um estudo qualitativo.

\subsection{Coleta e interpretação dos dados}

A coleta de dados foi realizada diretamente nos portais das prefeituras, durante os meses de janeiro e fevereiro de 2016 e com vistas ao Índice de Transparência da Gestão Pública Municipal (ITGP-M). Inicialmente realizou-se um levantamento dos portais oficiais existentes para cada uma das capitais dos 26 estados-membros e o Distrito Federal.

Os portais eletrônicos das capitais brasileiras, incluindo o Distrito Federal, foram avaliados conforme o ITGP-M, mensurado pela a soma dos pontos das seis categorias, que aborda desde as informações básicas dos municípios, informações financeiras, contábeis e fiscais, con-

forme ilustra a Tabela 1. Cada categoria apresenta uma série de itens e caso o portal analisado apresente-os receberá a pontuação respectiva. 
Tabela 1. Itens do ITGP-M

\begin{tabular}{|c|c|c|c|}
\hline & CATEGORIAS & Itens & $\begin{array}{c}\text { Soma } \\
\text { Pontos }\end{array}$ \\
\hline • & Informações gerais sobre os municípios, gestor municipal e vereadores; & 8 & 10 \\
\hline • & Legislação Municipal e Instrumentos de planejamento Municipal; & 11 & 11 \\
\hline • & Informações financeiras, relatórios contábeis e fiscais; & 16 & 36 \\
\hline - & Interação com os cidadãos e com a sociedade; & 17 & 19 \\
\hline • & Análise do Portal do Município. & 7 & 7 \\
\hline • & Disponibilização de informações quantitativas e qualitativas sobre a gestão. & 60 & 60 \\
\hline & Geral & 119 & 143 \\
\hline
\end{tabular}

Fonte: CRUZ et al. (2012)

\section{ANÁLISE DOS RESULTADOS}

Observa-se que dentre os portais das capitais brasileiras analisados a capital do Estado da Paraíba obteve um índice de 52\% na avaliação do seu portal, ou seja 75 do total do ITGP-M (Gráfico 1), e percebe-se que em relação aos resultados apresentados por Cruz et al. (2012) em que a maior pontuação foi de 122 pontos, para o município de Londrina (PR) ainda tem-se um caminho a percorrer.

João Pessoa, situada na Região Nordeste, com uma população de 723.515 habitantes (IBGE-2010), apresenta o nível de desenvolvimento alto e classificada como a capital mais transparente, apesar da distância entre o índice alcançado e o que realmente é esperado no ITGP-M. Porém, ao leva-se em consideração a pesquisa antes realizada por Costa e Torres (2014), nos municípios paraibanos, onde João Pessoa obteve 68 pontos, ou seja, 48\% do ITGP-M, é iminente verificar, que houve um avanço, com relação à pesquisa anterior.

Gráfico 1. ITGP-M da Capital Paraibana

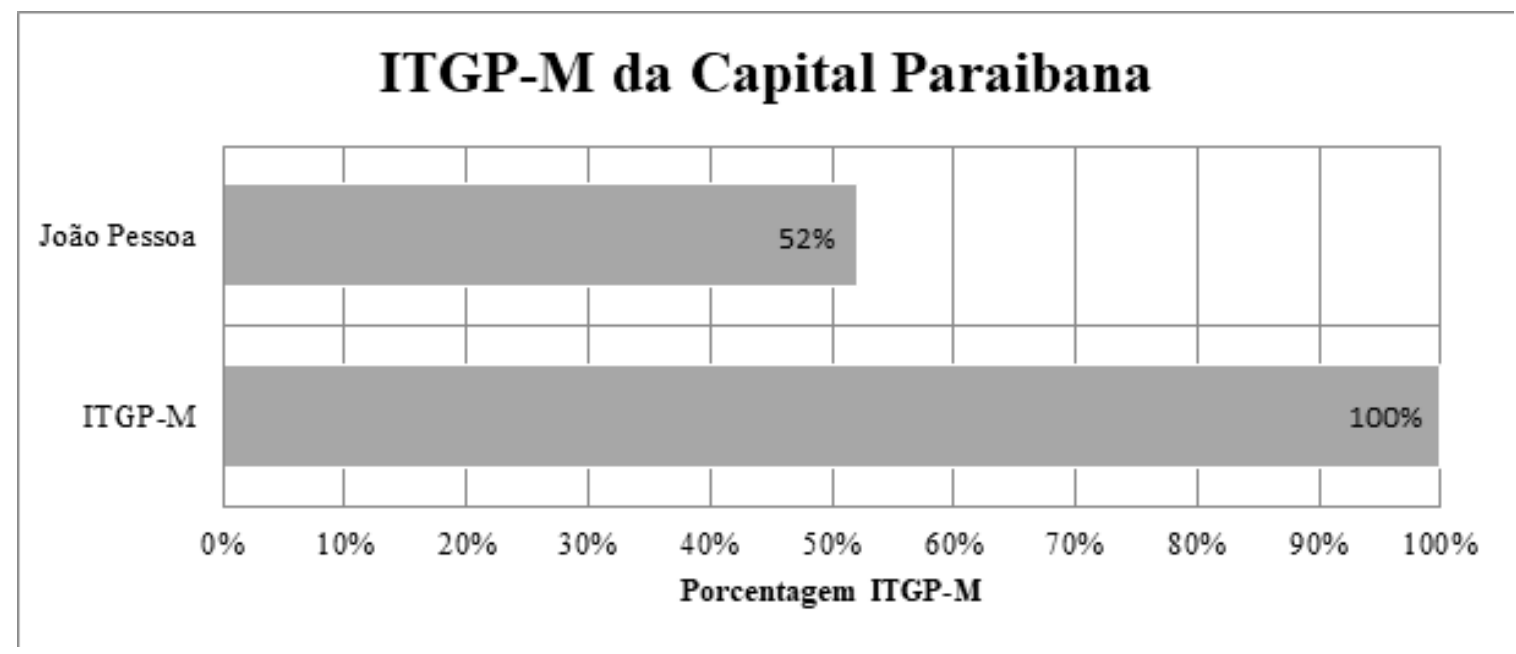

Fonte: elaborada pelos autores

A capital que obteve o segundo melhor índice de transparência foi Minas Gerais, que alcançou uma pontuação de 71 pontos dos 143 do ITGP-M, o equivalente a 50\% do esperado. Houve destaque também para as capitais Recife, Florianópolis e Porto Alegre - Gráfico 2, que alcançaram uma pontuação de 68 e 69 pontos do ITGP-M, o equivalente a 48\% do seu total (pontuação alcançada por João Pessoa em 2014, em pesquisa realizada por Costa e Torres, 2014). Os demais municípios obtiveram no máximo 46\% - (Paraná - Curitiba) do ITGP-M. 
Por sua vez, a capital com a menor pontuação, alcançou 17\% do ITGP-M (MaranhãoSão Luís) - Gráfico 2, um pouco melhor do que foi apresentado por Cruz et al. (2012), na análise realizada nos maiores municípios brasileiros, tendo em vista que a menor pontuação foi de 10,5\% do ITGP-M (Carapicuíba - SP).

Gráfico 2. Porcentagem alcançada nas Capitais analisadas em relação ao ITGP-M

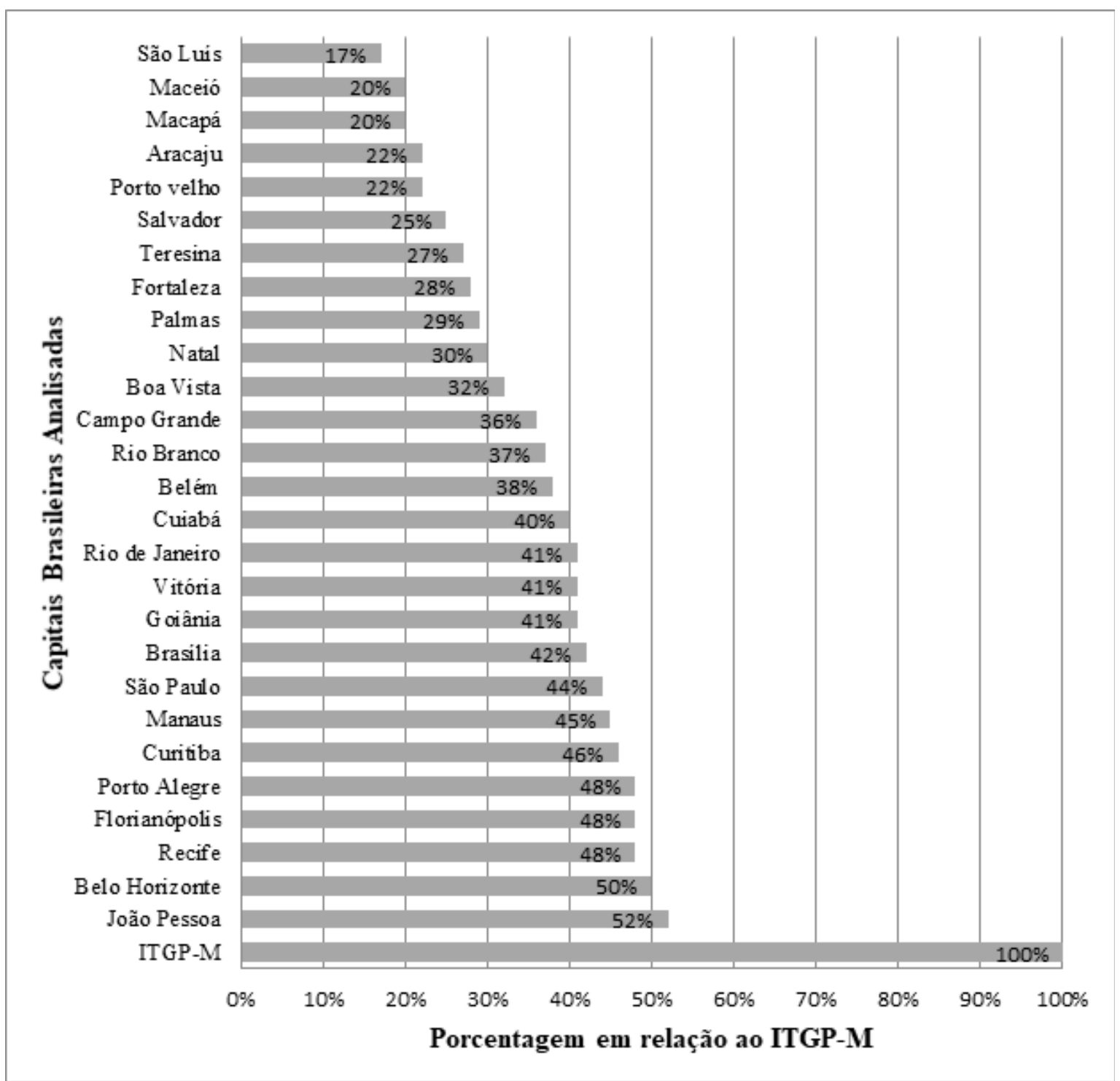

Fonte: Elaborado pelos autores (2016)

\subsection{Análise por região}

Levando em consideração a análise regional, verifica-se que as regiões com as maiores pontuações encontra-se a região nordeste e a região sul, com as Capitais da Paraíba e Minas Gerais, João Pessoa (52\%) e Belo Horizonte (50\%), respectivamente, Tabela 3.

As menores pontuações ficaram a cargo das regiões Norte e Nordeste, com Macapá (20\%) e São Luís (17\%), além de que na região Nordeste é perceptível a distância entre a melhor pontuação e a menor das nove capitais da região Nordeste (Tabela 3). 
Belo Horizonte foi a capital, dentre as capitais do Sudeste, que se destacou que se destacou, somou 71 pontos dos 143 do ITGP-M, ou seja, 50\% do seu total. Sendo a segunda capital mais transparente, nesta análise. Na Região Sul, foi possível verificar a proximidade entre os resultados encontrados, variando de 67 a 69 pontos do ITGP-M. Sendo Porto Alegre, o detentor da melhor pontuação, o equivalente a $48 \%$ do esperado no índice utilizado.

Tabela 3: Avaliação das capitais por região

\begin{tabular}{|c|c|c|c|}
\hline \multicolumn{4}{|c|}{ Avaliação das capitais por região } \\
\hline ITGP-M & Porcentagem & Capital analisada & Região \\
\hline 65 & $45 \%$ & Amazona - Manaus & Norte \\
\hline 55 & $38 \%$ & Pará - Belém & Norte \\
\hline 53 & $37 \%$ & Acre- Rio Branco & Norte \\
\hline 29 & $20 \%$ & Amapá- Macapá & Norte \\
\hline 75 & $52 \%$ & Paraíba - João Pessoa & Nordeste \\
\hline 69 & $48 \%$ & Pernambuco - Recife & Nordeste \\
\hline 43 & $30 \%$ & Rio Grande do Norte - Natal & Nordeste \\
\hline 25 & $17 \%$ & Maranhão - São Luiis & Nordeste \\
\hline 60 & $42 \%$ & Distrito Federal - Brasília & Centro - Oeste \\
\hline 59 & $41 \%$ & Goiás - Goiânia & Centro - Oeste \\
\hline 57 & $40 \%$ & Mato Grosso - Cuiabá & Centro - Oeste \\
\hline 52 & $36 \%$ & Mato Grosso do Sul - Campo Grande & Centro - Oeste \\
\hline 71 & $50 \%$ & Minas Gerais - Belo Horizonte & Sudeste \\
\hline 63 & $44 \%$ & São Paulo - São Paulo & Sudeste \\
\hline 59 & $41 \%$ & Rio de Janeiro - Rio de Janeiro & Sudeste \\
\hline 58 & $41 \%$ & Espírito Santo - Vitória & Sudeste \\
\hline 69 & $48 \%$ & Rio Grande do Sul - Porto Alegre & Sul \\
\hline 68 & $48 \%$ & Santa Catarina - Florianópolis & Sul \\
\hline 67 & $46 \%$ & Paraná - Curitiba & Sul \\
\hline
\end{tabular}

Elaborado pelos Autores (2016)

\subsection{Análise por categorias do ITGP-M}

Dado as seis categorias do índice de Transparência, convém destacar que dentre as capitais analisadas, apenas nas Categorias II, Cuiabá e Porto Velho obtiveram a maior pontuação possível e que na categoria $\mathrm{V}$, Curitiba também alcançou alcançaram o máximo esperado do ITGP-M. 
Tabela 4. Análise de acordo com as categorias do ITGP-M

\begin{tabular}{|c|c|c|c|c|c|}
\hline \multicolumn{6}{|c|}{ SUBITENS DO INSTRUMENTO DE COLETA DE DADOS } \\
\hline & Categoria & $\begin{array}{l}\text { Máximo } \\
\text { Possível }\end{array}$ & $\begin{array}{c}\text { Máximo } \\
\text { Observado } \\
\text { nos portais } \\
\text { analisados }\end{array}$ & $\begin{array}{l}\text { Capital que obte- } \\
\text { ve o maior índice } \\
\text { na categoria }\end{array}$ & Região \\
\hline \multirow[t]{10}{*}{ ITGP-M } & \multirow{3}{*}{$\begin{array}{l}\text { C1 - Informações gerais } \\
\text { sobre os municípios, gestor } \\
\text { municipal e vereadores }\end{array}$} & \multirow[t]{3}{*}{10} & \multirow[t]{3}{*}{6} & Campo Grande & Centro-Oeste \\
\hline & & & & Cuiabá & Centro-Oeste \\
\hline & & & & Florianópolis & Sul \\
\hline & \multirow{2}{*}{$\begin{array}{l}\text { C2 - Legislação Municipal e } \\
\text { Instrumentos de planejamen- } \\
\text { to Municipal }\end{array}$} & \multirow[t]{2}{*}{11} & \multirow[t]{2}{*}{11} & Cuiabá & Centro-Oeste \\
\hline & & & & Porto Velho & Norte \\
\hline & $\begin{array}{l}\text { C3 - Informações financeiras, } \\
\text { relatórios contábeis e fiscais }\end{array}$ & 36 & 30 & Vitória & Sudeste \\
\hline & \multirow{2}{*}{$\begin{array}{l}\text { C4 - Interação com os cida- } \\
\text { dãos e com a sociedade }\end{array}$} & \multirow[t]{2}{*}{19} & \multirow[t]{2}{*}{12} & João Pessoa & Nordeste \\
\hline & & & & Salvador & Nordeste \\
\hline & $\begin{array}{l}\text { C5 - Análise do Portal do } \\
\text { Município }\end{array}$ & 7 & 7 & Curitiba & Sul \\
\hline & $\begin{array}{l}\text { C6 - Disponibilização aos } \\
\text { cidadãos de informações } \\
\text { quantitativas e qualitativas } \\
\text { sobre a gestão }\end{array}$ & 60 & 32 & Belo Horizonte & Sudeste \\
\hline
\end{tabular}

Fonte: Elaborado pelos Autores (2016)

Ao analisar as capitais que disponibilizaram mais informações de acordo com as categorias do ITGP-M, percebe-se que não ocorreu de uma única capital se destacar em todas as categorias. Desta forma, as capitais da região Centro-oeste tende a disponibilizar mais informações em seus portais de forma geral, enquanto o destaque da região nordeste, tem-se a preocupação do diálogo mais próximo com a sociedade. Enquanto isso, a região Sudeste destaca-se por divulgar informações relacionadas a finanças e relatórios contábeis e fiscais, Tabela 4.

\subsection{ITGP-M x População x IDH}

Após analisar os portais e classifica-los quanto ao nível de transparência de acordo com o ITGP-M, verifica-se em que medida a população e o desenvolvimento social, representado pelo IDH, poderiam ser considerados fortes indícios para explicar os níveis de transparência alcançados pelas capitais brasileiras.

\subsubsection{População}

Na Região Norte, entre as capitais mais populosas, a capital do Amazonas possui uma população de 1.802.014 de habitantes obteve 65 pontos na análise de seu portal. Além desta, Belém, com população de 1.393 .399 habitantes, obteve 55 pontos na análise do portal. Assim, levando em consideração, estes dois aspectos, verifica-se que as capitais mais populosas da região norte, também alcançaram uma boa pontuação no ITGP-M, em seus portais municipais.

$\mathrm{Na}$ Região Nordeste, as capitais mais populosas não foram as que se destacaram na avaliação de seus portais com o ITGP-M, tendo em vista que João Pessoa, a capital paraibana, obteve a maior pontuação em seu portal, enquanto que as mais populosas: Salvador, Fortaleza e Recife, alcançaram respectivamente o ITGP-M de 36, 40 e 69 pontos. 
Na Região Centro-Oeste, as Capitais mais populosas também alcançaram uma boa pontuação no ITGP-M. Brasília e Goiânia, foram os destaques. A Capital mais populosa da região sudeste, a capital de São Paulo, não necessariamente alcançaram a melhor pontuação no ITGP-M, com 63 pontos, entretanto, a terceira capital mais populosa da região sudeste alcançou a melhor pontuação ITGP-M- 71. As capitais da região sul alcançaram boas pontuações no ITGP-M, levando em consideração a população, verifica-se que tanto a capital mais populosa Porto Alegre - RS, quanto a menos populosa Florianópolis - SC, ficaram com o ITGP-M 69 e 68 , respectivamente.

Isto posto, conclui-se que dentre as três mais populosas temos São Paulo, Rio de Janeiro, e Salvador, alcançaram os seguintes ITGP-M 63, 59 e 36, não sendo necessariamente as melhores pontuações entre as capitais analisadas. Entre as três capitais menos populosas, Palmas, Boa Vista e Rio Branco, alcançaram no ITGP-M, 42, 46 e 53, pontos.

Tabela 5: Variável - IDH

\begin{tabular}{|c|c|c|c|c|c|}
\hline \multicolumn{6}{|c|}{ ITGP-M X POPULAÇÃO } \\
\hline Sigla & Estado & Capital & $\begin{array}{l}\text { População } 2010 \\
\text { - IBGE }\end{array}$ & $\begin{array}{l}\text { ITGP-M apre- } \\
\text { sentado }\end{array}$ & Região \\
\hline AM & Amazonas & Manaus & 1.802 .014 & 65 & Norte \\
\hline PA & Pará & Belém & 1.393 .399 & 55 & Norte \\
\hline RO & Rondônia & Porto Velho & 428.527 & 32 & Norte \\
\hline $\mathrm{AP}$ & Amapá & Macapá & 398.204 & 29 & Norte \\
\hline $\mathrm{AC}$ & Acre & Rio Branco & 336.038 & 53 & Norte \\
\hline $\mathrm{RR}$ & Roraima & Boa Vista & 284.313 & 46 & Norte \\
\hline TO & Tocantins & Palmas & 228.332 & 42 & Norte \\
\hline BA & Bahia & Salvador & 2.675 .656 & 36 & Nordeste \\
\hline $\mathrm{CE}$ & Ceará & Fortaleza & 2.452 .185 & 40 & Nordeste \\
\hline PE & Pernambuco & Recife & 1.537 .704 & 69 & Nordeste \\
\hline MA & Maranhão & São Luís & 1.014 .837 & 25 & Nordeste \\
\hline $\mathrm{AL}$ & Alagoas & Maceió & 932.748 & 29 & Nordeste \\
\hline PI & Piauí & Teresina & 814.230 & 39 & Nordeste \\
\hline RN & \begin{tabular}{|l} 
Rio Grande do \\
Norte \\
\end{tabular} & Natal & 803.739 & 43 & Nordeste \\
\hline PB & Paraíba & João Pessoa & 723.515 & 75 & Nordeste \\
\hline SE & Sergipe & Aracaju & 571.149 & 32 & Nordeste \\
\hline DF & Distrito Federal & Brasília & 2.570 .160 & 60 & Centro-Oeste \\
\hline $\mathrm{GO}$ & Goiás & Goiânia & 1.302 .001 & 59 & Centro-Oeste \\
\hline MS & $\begin{array}{l}\text { Mato Grosso do } \\
\text { Sul }\end{array}$ & Campo Grande & 786.797 & 52 & Centro-Oeste \\
\hline MT & Mato Grosso & Cuiabá & 551.098 & 57 & Centro-Oeste \\
\hline $\mathrm{SP}$ & São Paulo & São Paulo & 11.253 .503 & 63 & Sudeste \\
\hline $\mathrm{RJ}$ & Rio de Janeiro & Rio de Janeiro & 6.320 .446 & 59 & Sudeste \\
\hline MG & Minas Gerais & Belo Horizonte & 2.375 .151 & 71 & Sudeste \\
\hline ES & Espírito Santo & Vitória & 327.801 & 58 & Sudeste \\
\hline PR & Paraná & Curitiba & 1.751 .907 & 66 & Sul \\
\hline RS & $\begin{array}{l}\text { Rio Grande do } \\
\text { Sul } \\
\end{array}$ & Porto Alegre & 1.409 .351 & 69 & Sul \\
\hline $\mathrm{SC}$ & Santa Catarina & Florianópolis & 421.240 & 68 & Sul \\
\hline
\end{tabular}


Elaborado pelos Autores (2016)

Nota 1: Os Dados referentes a quantidades de habitantes foram retirados das informações disponibilizadas no site do IBGE (2010).

Neste sentido, ao relacionar população e o nível de transparência (ITGP-M), percebe-se que a variável população por si só, não explica a divulgação de informações por meio dos portais de transparência para a sociedade, tendo em vista que algumas capitais menos populosas, apresentaram pontuação maior no ITGP-M, do que algumas capitais mais populosas.

\subsection{2 Índice de Desenvolvimento Humano (IDH)}

Renda, educação e saúde são as três dimensões básicas que o IDH leva em consideração no progresso a longo prazo, que relacionamos com os índices alcançados nas capitais brasileiras, verificando se existe associação com a transparência apresentada nos portais municipais.

Classificados como altos no nível de desenvolvimento humano, o IDH das capitais da região Norte variou entre 0,788 e 0,727 , os primeiros melhores pontuados no IDH, não necessariamente alcançaram os melhores ITGP-M. Na região nordeste, o IDH das capitais variou entre 0,772 e 0,721, porém o melhor índice do ITGP-M que ficou com a capital da Paraíba, João Pessoa ficou na quarta posição levando em consideração o IDH das capitais da região nordeste. Com o IDH classificado como muito alto, no nível de desenvolvimento, Brasília, capital do Distrito federal obteve o melhor ITGP-M, com 60 pontos, da região Centro-Oeste.

Relacionando o IDH com o ITGP-M na região Sudeste, verificamos que a capital do Espirito Santo, Vitória, com o melhor IDH alcançou a menor pontuação no ITGP-M, desta região, com 58 pontos. Classificadas no nível de desenvolvimento muito alto, as capitais da região Sul, obtiveram no ITGP-M uma pontuação que vaiou entre 66 e 69 pontos, onde a melhor classificada no IDH, Florianópolis - SC alcançou 68 pontos.

Tabela 6: Variável - IDH

\begin{tabular}{|l|l|l|l|l|}
\hline \multicolumn{2}{|c|}{$\begin{array}{c}\text { ITGP-M X IDH } \\
\text { GP-M }\end{array}$} & \multicolumn{1}{|c|}{ Região } & \multicolumn{1}{c|}{ Capital } & \multicolumn{1}{c|}{ IDH } \\
\hline $52 \%$ & Nordeste & Paraíba & João Pessoa & Alto \\
\hline $50 \%$ & Sudeste & Minas Gerais & Belo Horizonte & Muito Alto \\
\hline $48 \%$ & Nordeste & Pernambuco & Recife & Alto \\
\hline $48 \%$ & Sul & Santa Catarina & Florianópolis & Muito Alto \\
\hline $48 \%$ & Sul & Rio Grande do Sul & Porto Alegre & Muito Alto \\
\hline $46 \%$ & Sul & Paraná & Curitiba & Muito Alto \\
\hline $45 \%$ & Norte & Amazonas & Manaus & Alto \\
\hline $44 \%$ & Sudeste & São Paulo & São Paulo & Muito Alto \\
\hline $42 \%$ & Centro-Oeste & Distrito Federal & Brasília & Muito Alto \\
\hline $41 \%$ & Centro-Oeste & Goiás & Goiânia & Alto \\
\hline $41 \%$ & Sudeste & Espirito Santo & Vitória & Muito Alto \\
\hline $41 \%$ & Sudeste & Rio de Janeiro & Rio de Janeiro & Alto \\
\hline $40 \%$ & Centro-Oeste & Mato Grosso & Cuiabá & Alto \\
\hline $38 \%$ & Norte & Pará & Belém & Alto \\
\hline $37 \%$ & Norte & Acre & Rio Branco & Alto \\
\hline $36 \%$ & Centro-Oeste & Mato Grosso do Sul & Campo Grande & Alto \\
\hline
\end{tabular}




\begin{tabular}{|l|l|l|l|l|}
\hline $32 \%$ & Norte & Roraima & Boa Vista & Alto \\
\hline $30 \%$ & Nordeste & $\begin{array}{l}\text { Rio Grande do } \\
\text { Norte }\end{array}$ & Natal & Alto \\
\hline $29 \%$ & Tocantins & Palmas & Alto \\
\hline $28 \%$ & Norte & Ceará & Fortaleza & Alto \\
\hline $27 \%$ & Nordeste & Piauí & Teresina & Alto \\
\hline $25 \%$ & Nordeste & Bahia & Salvador & Alto \\
\hline $22 \%$ & Norte & Rondônia & Porto Velho & Alto \\
\hline $22 \%$ & Nordeste & Sergipe & Aracaju & Alto \\
\hline $20 \%$ & Norte & Amapá & Macapá & Alto \\
\hline $20 \%$ & Nordeste & Alagoas & Maceí́ & Alto \\
\hline $17 \%$ & Nordeste & Maranhão & São Luís & Alto \\
\hline
\end{tabular}

Elaborado pelos Autores (2016)

Das 27 capitais brasileiras analisadas, apenas 7 possuem IDH considerado Muito Alto, e dentre estas, a pontuação variou entre $41 \%$ a $50 \%$ do ITGP-M, onde as que ficaram nas extremidades desta porcentagem foram Belo Horizonte - MG com 71 pontos, ou seja 50\% do ITGP-M e Vitória - ES com 58 pontos, 41\% do ITGP-M, ambas situadas na região sudeste.

\section{CONCLUSÃO}

A presente pesquisa teve como objetivo geral a investigação do nível de transparência nos portais das prefeituras municipais das capitais brasileiras, para alcançá-lo, foi necessário analisar se todas as capitais continham portais eletrônicos oficiais; analisar os portais das prefeituras das capitais brasileiras, tendo como base o ITGP-M, verificando se os portais continham ou não as informações que compõem este índice, criando assim um ranking da porcentagem alcançada por cada capital brasileira e por fim, relacionar se existem evidências que a transparência desses municípios está relacionada a outras variáveis, tais como a população e o IDH.

O ITGP-M quantifica a transparência em 100\%, quando assomados os 143 pontos estabelecidos em cada um dos seus critérios. Esta pontuação afere o nível do portal eletrônico para cada item avaliado. Desta forma, foi por meio desse índice, que as transparências dos portais das capitais foram mensuradas.

Verificou-se que todas as capitais brasileiras apresentam um portal eletrônico oficial e isto viabilizou a realização da pesquisa, dentre os resultados a capital paraibana, João Pessoa, obteve a maior pontuação, porém em consideração ao ITGP-M, quando são esperados 143 pontos, está capital totalizou 75 pontos, ou seja, $52 \%$ da pontuação máxima.

A porcentagem alcançada pelas capitais brasileiras ficou entre 17\% (São Luís - MA) e $52 \%$ (João Pessoa - PB). Levando em consideração a região, certificou-se que na região Norte, houve o destaque para a capital de Amazonas, Manaus, com 65 pontos do ITGP-M; na Região Nordeste, o destaque ficou para João Pessoa - PB; Na Região Centro-Oeste, a pontuação variou entre $42 \%$ e $36 \%$ do ITGP-M; Na Região Sudeste encontrou a segunda melhor avaliada, Belo Horizonte - MG, com 50\% do ITGP-M; Já na Região Sul, houve quase um empate técnico entre Porto Alegue - RS e Florianópolis-SC, com 69 e 68 pontos do ITGP-M, respectivamente. Relacionando os resultados do ITGP-M, com variáveis como população e IDH, conclui-se que:

População: na região Norte as capitais mais populosas apresentaram resultados de maior transparência (Manaus e Belém), no Nordeste as capitais mais populosas apresentaram resultados de menor transparência (Salvador e Fortaleza) comparadas a João Pessoa, na região 
Centro-Oeste a capital mais populosa obteve o maior resultado de transparência (Goiânia), no Sudeste as capitais mais populosas obtiveram menor indicador de transparência (São Paulo e Rio de Janeiro) comparadas a Belo Horizonte, e por fim, na região Sul ocorreu o que pode ser considerado um empate técnico entre as capitais analisadas.

IDH: as capitais brasileiras apresentam IDH alto ou muito alto, sendo que o maior ITGP-M ficou com a capital da Paraíba, João Pessoa, que possui IDH alto, enquanto a segunda melhor colocação ficou com a capital de Minas Gerais, Belo Horizonte, que tem IDH muito alto.

Ou seja, os resultados são inconclusivos visto que não existe alguma evidência que a transparência de um município está relacionada ao tamanho da população ou IDH, pela importância do objeto de pesquisa e incipiência da temática, sugere-se que pesquisas futuras sejam realizadas nesse sentido.

O que se pode concluir é que temos caminhado em sentido a transparência pública, porém o caminho percorrido ainda é pequeno em comparação ao que é detalhado na legislação brasileira, quando determina que as informações devem estar dispostas em portais tornando a transparência ativa. A lei mais recente, a LAI - Lei de Acesso a Informação (Lei n 12.527, de 18 de novembro de 2011), fala que "o acesso é a regra e o sigilo, a exceção", assim atestamos que a busca pelo cumprimento da regra, ainda caminha a passos curtos, razão pela qual chama a atenção para a necessidade de medidas fiscalizadoras e reguladoras mais rígidas. 


\section{REFERÊNCIAS BIBLIOGRÁFICAS}

ALÓ, C. C. Uma Abordagem para Transparência em Processos Organizacionais Utilizando Aspectos. 2009. 328f. Tese (Doutorado em Ciências - Informática) Departamento de Informática, Pontifícia Universidade Católica do Rio de Janeiro, Rio de Janeiro, 2009.

ALVES, D. P. Acesso à informação pública no Brasil: um estudo sobre a convergência e a harmonia existentes entre os principais instrumentos de transparência e de controle social. $6^{\circ}$ concurso de monografias da CGU. 2011.

Brasília: Secretaria de Orçamento Federal, 2008. 98 p. Disponível em: Acesso em 20 nov. 2015.

BRASIL. Constituição da República Federativa do Brasil de 1988. Disponível em: http:// www.planalto.gov.br/ccivil_03/Constituicao/Constituicao.htm. Acesso em: 28 de nov. 2013.

. Lei Complementar $n^{\circ} 101$, de 4 de maio de 2000. Disponível em: http://www.planalto.gov.br/ccivil_03/leis/lcp/lcp101.htm . Acesso em: 28 de nov. 2013.

Lei Complementar $n^{\circ} 131$, de 27 de maio de 2009. Disponível em: http://www.planalto.gov.br/ccivil_03/Leis/LCP/Lcp131.htm. Acesso em: 28 de nov. 2013.

Lei de Acesso a Informações Públicas. Lei n ${ }^{\circ}$ 12.527, de 18 de novembro de 2011. Disponível em: http://www.planalto.gov.br/ccivil_03/_ato20112014/2011/lei/112527.htm. Acesso em: 28 de nov. 2013.

CADBURY COMMITEE. Report of the commitee on the financial aspects of corporative governance. London, 1992.

CAVALCANTE, R. J. Transparência do orçamento público brasileiro: exame dos documentos orçamentários da União e uma proposta de estrutura para o orçamento cidadão. 2008

CAMPOS, A. M. Accountability: Quando poderemos traduzi-la para o português? Revista de Administração Pública, Rio de Janeiro, 1990.

COSTA, J. M. TORRES, F. J. V. Transparência Pública: Uma Avaliação dos Portais das Prefeituras Paraibanas sob a Perspectiva do ITGP-M. Anais do $1^{\circ}$ Congresso UnB de Contabilidade e Governança. Universidade de Brasília, 2014.

CRUZ, C. F.; FERREIRA, A. C. de S.; SILVA, L. M.; MACEDO, M. A. da S. Transparência da gestão pública municipal: um estudo a partir dos portais eletrônicos dos maiores municípios brasileiros. Revista de Administração Pública - RAP, v. 1, n. 46, p. 153-176, 2012.

FIGUEIREDO, V. S.; SANTOS, W. J. L. Transparência e participação social da gestão pública: análise crítica das propostas apresentadas na $1^{a}$ Conferência Nacional sobre Transparência Pública. Revista de Contabilidade e Controladoria, UFPR, Curitiba, PR, v. 6, n. 1, p. 73-88, 2014.

GIL, A. C. Métodos e Técnicas de Pesquisa Social. 6. ed. São Paulo: Atlas, 2008.

GRAU, N. C. A democratização da administração pública: os mitos a serem vencidos. Cadernos FLEM - Gestão Pública e Participação, v.1, n. 8, p. 13-59. 2005.

INSTITUTO BRASILEIRO DE GEOGRÁFIA E ESTATÍSTICA - IBGE. Censo demográfico 2010. Disponível em:http://www.ibge.gov.br/home/estatistica/populacao/censo2010/default. 
shtm. Acesso em: 28 Nov. 2013.

MARQUES, M. C. C. Aplicação dos Princípios da Governança Corporativa ao Sector Público. RAC, v. 11, n. 2, 2007

MARCONI, M. A.; LAKATOS, E. M. Fundamentos de Metodologia Científica. São Paulo: Atlas, 2007.

PAIVA, C. P. de R.; ZUCCOLOTTO, R. Índice de transparência fiscal das contas públicas dos municípios obtidos em meios eletrônicos de acesso público. Anais do XXXIII Encontro da ANPAD. São Paulo: ANPAD, 2009.

PESTANA, M. Direito Administrativo Brasileiro. 3a . Ed. Rio de Janeiro: Elsevier, 2012.

PLATT NETO, O. A.; CRUZ, F. da; VIEIRA, A; L. Transparência das contas públicas: um enfoque no uso da internet como instrumento de publicidade na UFSC. Revista Contemporânea de Contabilidade, Florianópolis, v. 1, n. 5, p. 135-146, 2006

RAUPP, F. M.; PINHO, J. A. G. Construindo a accountability em portais eletrônicos de câmaras municipais: um estudo de caso em Santa Catarina. FGV. EBAPE. 2010.

SACRAMENTO, A. R. S.; PINHO, J. A. G. Transparência na administração pública: o que mudou depois da lei de responsabilidade fiscal? Um estudo exploratório em seis municípios da região metropolitana de Salvador. Revista de Contabilidade da UFBA, v. 1, n. 1, p. 48-61, 2007.

SLOMSKI, V. Governança corporativa e governança na gestão pública. Atlas, 2008.

SOUZA, R. M. Controle social e reprodução capitalista: polêmicas e estratégias contemporâneas. Revista Temporalis, Brasília (DF), v. 2, n. 20, p. 49-76, 2010.

SUZART, J. A. S. Ser ou não ser independente? Um estudo exploratório sobre a independência das instituições superiores de auditoria e o nível de transparência fiscal dos países. Revista Universo Contábil. v. 8, n. 3, p. 24-39, 2012.

TAVARES, M. C. B; MARTINS, P. E. M; FIGUEIREDO, V. da S. Controle Social no Brasil: A administração política como transformadora da percepção do gestor público na sua relação com a sociedade. Revista Brasileira de Administração Política. v.6, n. 2, 2013.

TIMMERS, H. Government Governance: Corporate governance in the public sector, why and how? The Netherlands Ministry of Finance. In 9th Fee Public Sector Conference. 2000.

VERGARA, S. C. Projetos e Relatórios de Pesquisa em Administração. $12^{\circ}$ edição, São Paulo: Editora Atlas. 2010. 